\title{
Network-driven Context in User-driven Innovation
}

\author{
Yumiko Kinoshita ${ }^{1}$, Osamu Sudoh $^{2}$ \\ ${ }^{1}$ Doctoral Student, The University of Tokyo, Graduate School of Interdisciplinary \\ Informatics \\ ${ }^{2}$ Professor, The University of Tokyo, Graduate School of Interdisciplinary \\ Informatics
}

\begin{abstract}
As new networks such as sensor and grid computing are developed, service providers, intermediaries, and users are exposed to an increasing number of contexts, which is a set of information that affects users' behavior and value system in accordance with a network they belongs to. This paper proposes that citizens' contextual data should be collected based on service quality, satisfaction, and technological acceptance model in administrative IT investment and management framework. The main objectives are that the usage rate of online applications increases, and that multi-channel service delivery and One-stop Portal is efficiently and effectively offered in Japanese e-Gov initiative. We present a methodology of visualizing citizens' trust and continual usage intentions in light of an existing service science model as well as providing governance across multiple administrative agencies and organizations.
\end{abstract}

\section{Introduction}

The development of Information Technology (IT) has already come to the point at which we require an enhancement of current socio-economic framework, so called 'open economy'. With the introduction of sensor networks, grid computing, pervasive computing, and sophisticated search and semantic algorithms, individuals belong to an increasing number of networks of completely different natures.

In our existing framework of network analysis, this issue is addressed typically as an environmental and complex ecosystem as well as 'structural attributes' associated with the diverse system [1]. Structure reduces risk in a system. However, users not

Please use the following format when citing this chapter:

Kinoshita, Y., Sudoh, O., 2008, in IFIP International Federation for Information Processing, Volume 286; Towards Sustainable Society on Ubiquitous Networks, eds. Oya, M., Uda, R., Yasunobu, C., (Boston: Springer), pp. 245-252. 
only involve in production or provision process of products and/or services in a value chain to promote innovation, but they also generate innovation by combining, copying, or switching the contexts they belong to. Contexts are created as a reflection of network, and innovation will occur far more at micro level as the number of network increases. This type of innovation depends less on social or economic structure than the conventional concept of user innovation. Therefore, we must be aware of possible effects of such innovation to bring in our society and economy, and provide tools to promote this user-driven innovation based on the contexts in addition to the analysis of path, distance, or contents provided via network. The following section will discuss the relationship of network, context, and innovation by taking e-Government as a case study.

\section{Network-driven Context}

In recent years, a research field called 'e-Science' is gathering attention. The service sector consists of approximately $75 \%$ of most major economies. Various research initiatives are underway to clarify how to improve the productivity of the service sector and enhance innovative capabilities. Freeman and Soete [2] state that we should reconstruct our understanding on major economic indexes including Gross Domestic Product (GDP) due to the rise of the service economy. Under such conditions, eScience plays a role to consort efforts for finding a mechanism and achieving agility so that both providers and consumers maximize utility especially in IT services.

From the viewpoint of macroeconomics, it is important to create a service portfolio to provide services with diversification, differentiation, and competitive quality. Service sectors can work together with users to gain maximum return for an area where service is being provided. Some services are not tradable. Therefore, geographical elements must be considered in terms of productivity and opportunities for creating new services. The geospatial elements achieve two goals: to increase return on investment per area and to gain competitiveness in a global market by overcoming locality. To support these objectives, IT is used to create access to network among local entities as well as among actors in the global market. In a 'service ecosystem', which is an important concept for 'Service Science', value networks encompass implications to user's satisfaction regarding the quality of services including both tangibles and intangibles i.e. skills and knowledge of users [3].

From micro-level perspective, agent-based modeling is often used to design web applications. In a complex system, multi-agent systems (MAS) specify the protocols for interaction and agent's strategy [4]. MAS achieve outcome, which is not Paretodominated by any other outcome, and maximizes social welfare (ibid.). Such systems are implemented when there are multiple sets of preferences and values for a particular agent. For example, automated guided vehicle interacts with environment to achieve competing goals i.e. optimal speed and comfortableness of driving.

Context is a set of information which affects an agent or member's behavior and the value systems that the agent or member hold over geography and time. An agent or member belongs to several networks, each of which creates a context as its reflection. In US, the federal government is investing in building clinical data management capabilities such as electronic medical record (EMR), personal medical record (PMR), and remote healthcare system using mobile communication devices and sensors. Citi- 
zens can access one-stop public service portal, access provider's network, or go to Medline, a database of life sciences and biomedical information. Citizens, providers, and payers have different contexts in relation to the networks they belong to. As such, multi-level and multi-layered stakes are involved and innovation occurs when each actor actively engages in identifying contexts and restructuring on their own initiatives.

This is a different type of user innovation from 'prosumers' presented by Toffler [5]. 'Prosumers' involve in production and/or provision process for a particular product or service. On the other hand, user-driven innovation is created by switching, copying, reconfiguring, or combining network-driven contexts. With this in mind, it is necessary that socio-economic infrastructure is equipped with a capability to promote this context-oriented user-driven innovation with the presence of various networks.

\section{User-driven Innovation and Micro-level Governance}

The relationship of value and choice is under constant pressure for change in the open environment. Therefore, technologies should provide an ability to interpret behaviors of different members or agents in a network. This is a dynamic value recognition mechanism embedded in a system. Semantics and simulation technologies are tools for the communication with the system. Interoperability of different applications and standard protocols has been developed so that organizational activities could reduce multiplicity, or heterogeneity of knowledge, through consensus-building mechanism. However, user-driven innovation requires this multiplicity to be encouraged to increase the rate of knowledge production [6], and reflected to social common capital.

Governance is a part of the social capital, which enhances innovative capability of our society and economy. Social capital can be considered from the viewpoint of private and social effects, for example, in the case of healthcare according to Uzawa [7]. The private effect is expressed by the function of the ability of labor and a factor of production. It is optimized according to a utility function, in which an individual person chooses a combination of medical care and its quality subject to a budget constraint. Market equilibrium is achieved based on 'the sum of the levels of medical care provided by all medical institutions', production, labor, wage, demand and price of goods and services (ibid.). As for governance, it is a process of exercising control over the task of information processing in a hierarchy or organizational context [8]. Therefore, governance relates to the hierarchy, in which firms and organizations affect production and other factors.

Governance for network-driven context should be less hierarchical or structural so that user-driven innovation is obtained. Aoki [8] refers to 'relational contingent governance' with regard to the case of venture capital. If a user involves in innovation process as an entrepreneur, governance must be provided as a form of (virtual) symmetry. Symmetry is a method to manipulate structure, system, or domain with no observable change. When symmetrical contexts are presented within a network in addition to the relation of members or agents, users are exposed to the governance mechanism similar to the 'tournament effect' (ibid.). As for public services including healthcare, government agencies have a role to play in providing governance for contexts on behalf of individual member or agent in the network as a social common capital based on mutual trust so that structural void is filled within networks. 
The trustworthiness for each service provided by e-government infrastructure is determined by service quality, technical ability, benevolence, and integrity according to Benbasat et al. [9] who surveyed 647 e-government services in Canada. 'Empathy' and 'benevolence' are similar concepts to context. Both of which show the weakest correlation to 'user's trust' and 'continual use intention' among the other attributes (ibid.). It is assumed that the importance of context is not fully recognized by either users or government agencies. This situation poses an important question to ask. Is the existing e-government infrastructure equipped with necessary functions and management scheme to enhance public services and facilitate user innovation in the above-mentioned network-driven context? The following section will review eGovernment policy in Japan by focusing on one-stop portal and multi-channel service delivery from the viewpoint of IT investment and capital management.

\section{Socio-economic Architecture and Innovation}

In Japan, New IT Reform Strategy, developed in 2006, aims at developing the most efficient and usable e-Government in the world [10]. The first target is to increase the usage rate of online applications to $50 \%$ by 2010 . Secondly, the government will optimize operations and systems through cross-agency cooperation including the coordination of front and back offices. To achieve these goals, the government will particularly emphasize performance-based evaluation and Plan, Do, Check and Action (PDCA) cycle. By 2010, a standard model for service infrastructure will be developed, and One-stop Service Portal will be launched (See Figure 1). A part of such efforts is the visualization of administrative service value from user's viewpoint.

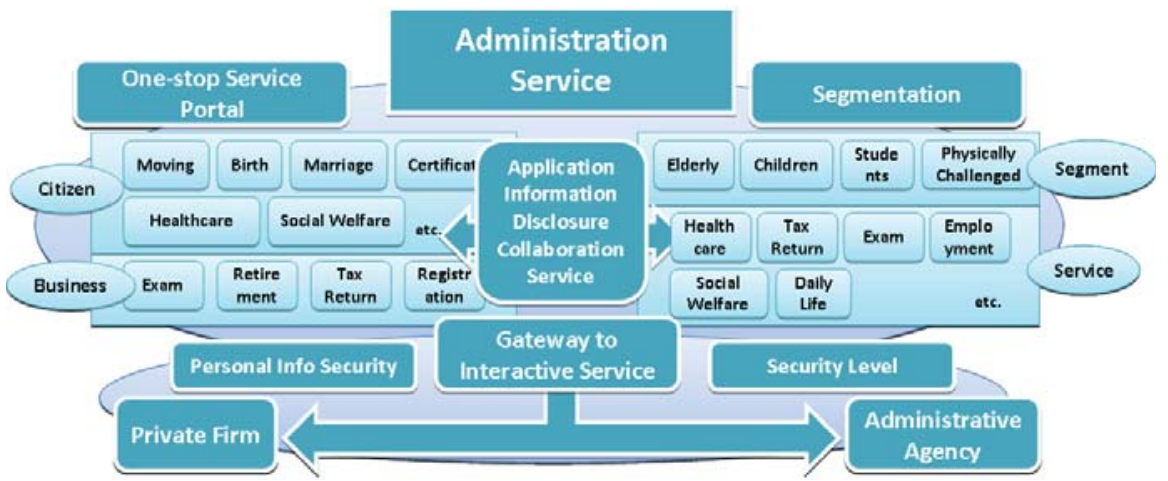

Figure 1 One-stop Service Portal and User Segmentation (Source: Created based on [11])

\subsection{Context-based Process Management for Administrative Services}

What is the best method for IT investment and capital management for the project of 
One-stop Portal and multichannel service delivery so that the benefit is visualized for users? The current evaluation system focuses on qualitative assessment based on user's expected value and perceived value. To manage the One-stop Service Portal in the most efficient and effective manner as well as to achieve user-driven innovation in the network-driven context, the process assessment can be improved as follows.

A proposed method is to extract and manage contextual information from the current system as Figure 2. Administrative organizations have improved their process and business toward government-wide optimization. Agency collects information on individual users, technological capability, and user's value systems with regard to a particular service, the agency designs appropriate service at micro level, and visualize values from user's viewpoint in the process evaluation. The overall benefits is captured in the impact evaluation from the viewpoint of economic, social, strategic, political, and innovative benefits [10] at macro level (for both users and the agency).

Through this process, multiple agencies coordinate their contracts to identify common service components to reduce overall investment costs and facilitate service delivery. In this proposed method, government agencies manage the cost and benefit of users based on context more than activity, process, component, or project. Administrative agencies may achieve the next level of transformation after activity-based reform and strategic organizational reform, in which IT investment and management can be implemented thoroughly from user's viewpoint at an organizational level.

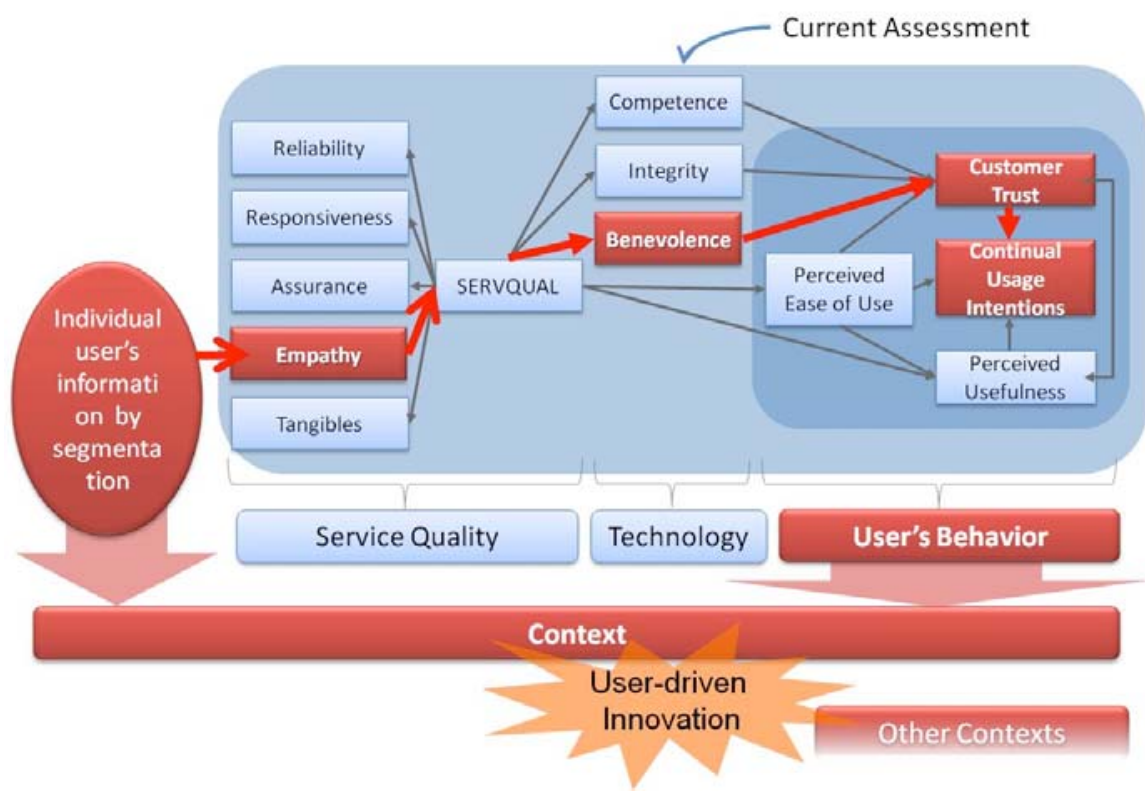

Figure 2 Context-based Management Approach for e-Government (Source: Created based on [9])

\subsection{Governance for Context-based Management}

Japan's IT management and evaluation scheme is influenced primarily by U.S. Enter- 
prise Architecture model. The above-mentioned context management can be understood within the framework of Federal Enterprise Architecture (FEA) Performance Reference Model (PRM) of Office of Management and Budget. In PRM, IT investment is planned, budgeted, and executed to achieve the lowest life-cycle cost and least risk [11]. The context-based assessment should be particularly useful for mixed life-cycle investment so that IT investment can be managed consistently across multiple systems. In addition, an interagency acquisition is often made based on a multiagency or government-wide contract to manage one investment project. Such multiagency collaboration investments require Line of Business (LoB) initiatives as well as Chief Information Officers (CIOs) to consort their efforts to analyze duplicate investments, gaps and opportunities. Because the context-based approach enables us to manage administrative service based on more than an activity or component, it will provide users with a clear picture on what stake they have with the investment.

When regulatory policy has a strong guidance for action across agencies, administrative agencies cope with the issue of multi-layered, multi-level stakes through regulatory power sharing based on certainty, proportionality, and procedures [14]. To overcome the challenge and serve diffuse interests rather than focusing on narrow program interests, IT plays a role to distinguish variables and common areas with regard to the value of administrative services. The variables identified through the context-based management are controlled by power sharing by LoB or CIOs. Thus, the balance between simplicity and multiplicity must be determined. When proper governance is implemented, it is easy to involve new stakeholders in policy debates and timely respond necessary policy change. It is important to balance competition policy, integration policy and market openness policy so that administrative agencies play a role to enforce the conflict-of-interest policy [14].

As discussed previously, user-driven innovation occurs when users engage in combining, copying, and restructuring various contexts. To enhance this process, service providers including administrative agencies must manage and visualize the context appropriately within their IT investment and management schemes. Governance of user-driven innovation will be obtained on P2P (peer-to-peer) bases over various types of networks when multiple symmetrical (or identical) contexts exist. Administrative agencies must play a role to collect data, analyze, and visualize from user's viewpoint so that this innovation and governance scheme will properly work (See Figure 3). 


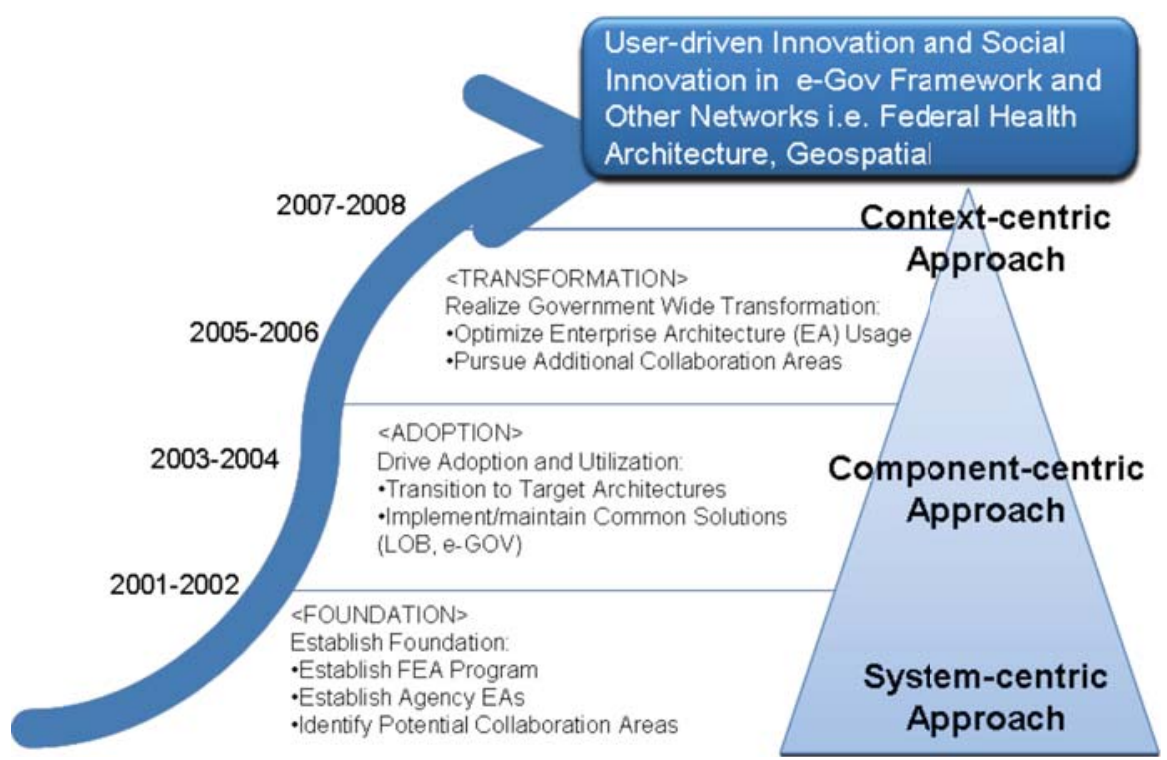

Figure 3 Federal Enterprise Architecture and Context (Source: Created based on [13, 15])

\section{Conclusion}

This paper argues the method of IT investment and management i.e. e-Government and social issues. This attempt will contribute to the most convenient and effective eGovernment from user's viewpoint. The concept of context can be implemented in administrative IT investment and management framework to increase the usage rate of online applications, and to offer multi-channel service delivery and One-stop Portal. As we have seen, network-driven context and user-driven innovation will bring the following benefits. First, the context data is clearly identified and visualized so that public service is provided from user's viewpoint. Secondly, the micro-level governance is implemented.

Lastly, it is also clear that the micro-level governance through providing the symmetrical mechanism must be further studied. Past researches mainly discuss value creation process and the role of services from the viewpoint of industry structure, value chain, and networks. Analysis of pathway, value clustering, and sub-networks have been focused on. The importance of context, which is a product of existing networks, should be carefully considered also. Collaborative, open innovation can be enhanced by integrating network-driven context and user-driven innovation as a form of governance and socio-economic infrastructure. Therefore, this argument is prerequisite for enhancing open innovation based on user's active engagement, and developing socio-economic framework based on service industries including administrative services. From this perspective, the relationship between network and context must be studied further so that research findings can be implemented in our network society as an institutional mechanism. 


\section{Reference}

1. May, M. R., Levin, A. S., Sugihara, G. (2008). Ecology for bankers. Nature, 451(21), 893-895.

2. Freeman, C., Soete, L. (2007). Developing science, technology and innovation indicators: what we can learn from the past. United Nations University; UNU-Merit Working Paper Series \#2007001.

3. Sawatani, Y. (2007). Research Service Ecosystems. Proceedings of PICMET 2007, 2763-2768.

4. Parkes, C. D., Dash, K. R., Jennings, R. N. (2003). Computational-Mechanism Design: A Call to Arms. IEEE Intelligent Systems, 18(6), 40-47.

5. Toffler, A., Toffler, H. (2006). Evolutionary Wealth. New York: Currency Doubleday.

6. Fujita, M. (2007). Towards The New Economic Geography In The Brain Power Society, Regional Science and Urban Economics, 37(2007), 482-490.

7. Uzawa, H. (2005). Economic Analysis of Social Common Capital. New York: Cambridge University Press, 322-358.

8. Aoki, M. (2001). Toward a Comparative Institutional Analysis. Boston: The MIT Press.

9. Benbasat, I., Cenfetelli, T. R., Tan, C. (2008). Building Citizen Trust towards e-Government Services: Do High Quality Websites Matter?. Proceedings of the 41st Hawaii International Conference on System Sciences - 2008, 1-10.

10. IT Strategic Headquarters (2006). New IT Reform Strategy: Realizing Ubiquitous and Universal Network Society Where Everyone Can Enjoy the Benefits of IT. Japan Prime Minister's Office.

11. Project Team for The Next Generation e-Public Service Infrastructure (2008). Resource document. The Government of Japan. http://www.kantei.go.jp/jp/singi/it2/nextg/meeting/dai3/pdf/siryou2.pdf Accessed 13 April 2008.

12. Sudoh, O., Gotoh, R., Akatsu, M., Yoshikawa, H., Nakagawa, T., Kinoshita, Y. (2007). Performance Measurement and Evaluation Framework for e-Government (To Be). In Public Service Analysis Group (eds.), e-Government Evaluation Committee's Report for the 2nd meeting (26 July 2007). Division of University Corporate Relations, The University of Tokyo.

13. The Office of Management and Budget Office of E-Government and Information Technology (2007). FEA Consolidated Reference Model, Document Version 2.3. Executive Office of the President.

14. OECD (2006). Public Governance. In OECD, Policy Framework for Investment: A Review of Good Practices, 233-258.

15. The Office of Management and Budget Office, (2005). Enabling Citizen-Centered Electronic Government 2005 - 2006 FEA PMO Action Plan. Executive Office of the President, March 2005. 